\title{
Heat transfer intensification of Zirconia/water nanofluid
}

\author{
Shajahan Mohamed Iqbal ${ }^{1}$, ChockalingamSundar Raj ${ }^{2}$, Sambandan \\ Arul $^{3}$,PalanisamyRathnakumar ${ }^{4}$ \\ ${ }^{1}$ Research Scholar,Faculty of Mechanical Engineering,Anna University,Chennai-25,Tamilnadu,India. \\ 1iqbalmech18@gmail.com \\ ${ }^{2}$ A.V.C. College of Engineering,Mannampandal,609305,Tamilnadu,India. \\ 2csundarraj@yahoo.com \\ ${ }^{3}$ Aksheyaa College of Engineering, Maduranthagam, 603314, Tamilnadu,India \\ 3dr.aruls@gmail.com \\ ${ }^{4}$ Navodaya Institute of Technology, Raichur, 584103.Karnataka, India. \\ 4rathnakumar1972@gmail.com
}

\begin{abstract}
This paper investigated convective heat transfer and friction factor of $\mathrm{ZrO}_{2} / \mathrm{H}_{2} \mathrm{O}$ nanofluid through a circular pipe under laminar flow condition with constant heat flux. Nanofluid is prepared for $0.5,0.75$ and $1 \%$ volume concentrations with Yttrium Oxide surfactant. Nanofluid's thermal conductivity and viscosity is measured by KD2 Pro thermal analyser and Brookfield viscometer respectively. Results showed that the thermal conductivity and viscosity increased with increase in particle volume concentration. These nanofluids are experimented in a forced convection system, first heat transfer characteristics of DI (Deionised) water under laminar flow in a copper tube measured, then using the different volume concentration nanofluids, results revealed that the enhanced Nusselt numbers of $21.09,28.05$ and $35.73 \%$ at the 0.5 , 0.75 and $1 \%$ volume concentrations, There is no excess penalty in pumping power and results showed less variations in friction factor for nanofluids compared tothe base fluid (DIWater).
\end{abstract}

\section{Indexing terms/Keywords}

Thermal conductivity, Viscosity, Convective heat transfer, $\mathrm{ZrO}_{2} / \mathrm{H}_{2} \mathrm{O}$ nanofluid,Zirconia.

\section{Academic Discipline And Sub-Disciplines}

Mechanical Engineering,Thermal Engineering.

\section{SUBJECT CLASSIFICATION}

Heat Transfer

\section{TYPE (METHOD/APPROACH)}

\section{Experimental Analysis}

\section{INTRODUCTION}

Earlier the heat transfer studies are restricted to suspension of milli or micro sized particle in the base fluid, But later in 1990s study ofnano sized particle is studied and it is dispersed in a base fluid like water, ethylene glycol and oil used for heat transfer augmentation[1]. Studies resulted in heat transfer coefficient augmentation in nanofluid than conventional fluid, it is recorded a tremendous development in automobile and industrial applications. Pak and Cho[2] studied on nanoparticles $\mathrm{Al}_{2} \mathrm{O}_{3}, \mathrm{TiO}_{2}$ suspended in water the Nusselt number is increased with increasing in volume concentration, enhancement of heat transfer increased up to $12 \%$ than pure water. Keblinski et al[3] experimentally investigated heat transfer mechanisms involved in nanofluid and inferred nanofluids are more ballistic than diffusive also suggested, experimental simulation approach is used to enhance the heat transfer applications. S.K.Das et al[4] experimentally investigated temperature effect on thermal conductivity of $\mathrm{Al}_{2} \mathrm{O}_{3}$-water and $\mathrm{CuO}$-water. Xuan and $\mathrm{Li}$ [5] observed experimentally that heat transfer coefficient increased phenomenally in nanofluid than water in turbulent flow. NileshPurohit[6] numerically studied the performance factor of Alumina, Titanium dioxide, Zirconia and showed entropy generation decreased under the same Reynolds number. AminrezaNoghrehabadi et al[8] reported Alumina/water in laminar flow and resulted in an increase of heat transfer up to $22.5 \%$ at $0.9 \%$ of volume concentration. M.A. Khairul[9] inferred that the stability of nanofluid depends on zeta potential and suggested improving the stability of nanofluid possibly with low viscosity and high thermal conductivity. B.Chitra and K.Satishkumar[10] compared single base fluid as water/copper oxide, double base fluid water and ethylene glycol with copper oxide nanoparticle and observed that $\mathrm{CuO/water} \mathrm{yielded} \mathrm{better} \mathrm{thermophysical} \mathrm{properties.} \mathrm{M} \mathrm{Chopkar[11]} \mathrm{investigated} \mathrm{Zirconia/water,Zirconia/EG} \mathrm{nanofluid} \mathrm{in}$ which Zirconia/EG nanofluid showed more thermal conductivity due to the higher viscosity of ethylene glycol(EG).Wesley Williams et al[12] experimentally studied Zirconia nanofluid,alumina nano fluid and showed nusselt number increased for both the nanofluids.

In this present work $\mathrm{ZrO}_{2} / \mathrm{H}_{2} \mathrm{O}$ nanofluid is employed in the closed loop system with laminar flow and studied the effect of nusselt number and friction factor. 


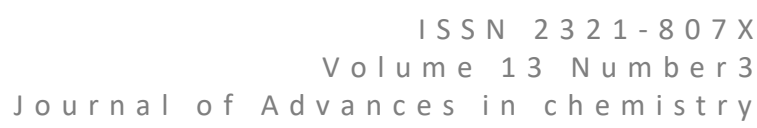

\section{Nanofluid preparation}

There are two methods to prepare nanofluid namely one step method and two step method. In one step method nanoparticle is synthesised, simultaneously dispersed in base fluid. In two step method, nanoparticle made by proper technique, then dispersed in base fluid. In this study, two step method is followed and DI water is used as base fluid. $\mathrm{ZrO}_{2}$ nanoparticle was purchased from AlfaAesar (UK). The properties of the $\mathrm{ZrO}_{2}$ nanoparticle is given below in the Table 1.

\section{Table 1.Properties of Zirconia Nanoparticle}

\begin{tabular}{|l|c|}
\hline Chemical formula & $\mathrm{ZrO}_{2}$ \\
\hline Shape & Sphere \\
\hline Mean diameter & $20 \mathrm{~nm}$ \\
\hline Density & $5600 \mathrm{~kg} / \mathrm{m}^{3}$ \\
\hline Thermal conductivity & $2.6 \mathrm{~W} / \mathrm{m}-\mathrm{K}$ \\
\hline Specific heat & $418 \mathrm{~J} / \mathrm{kg}-\mathrm{K}$ \\
\hline Purity & $99 \%$ \\
\hline
\end{tabular}
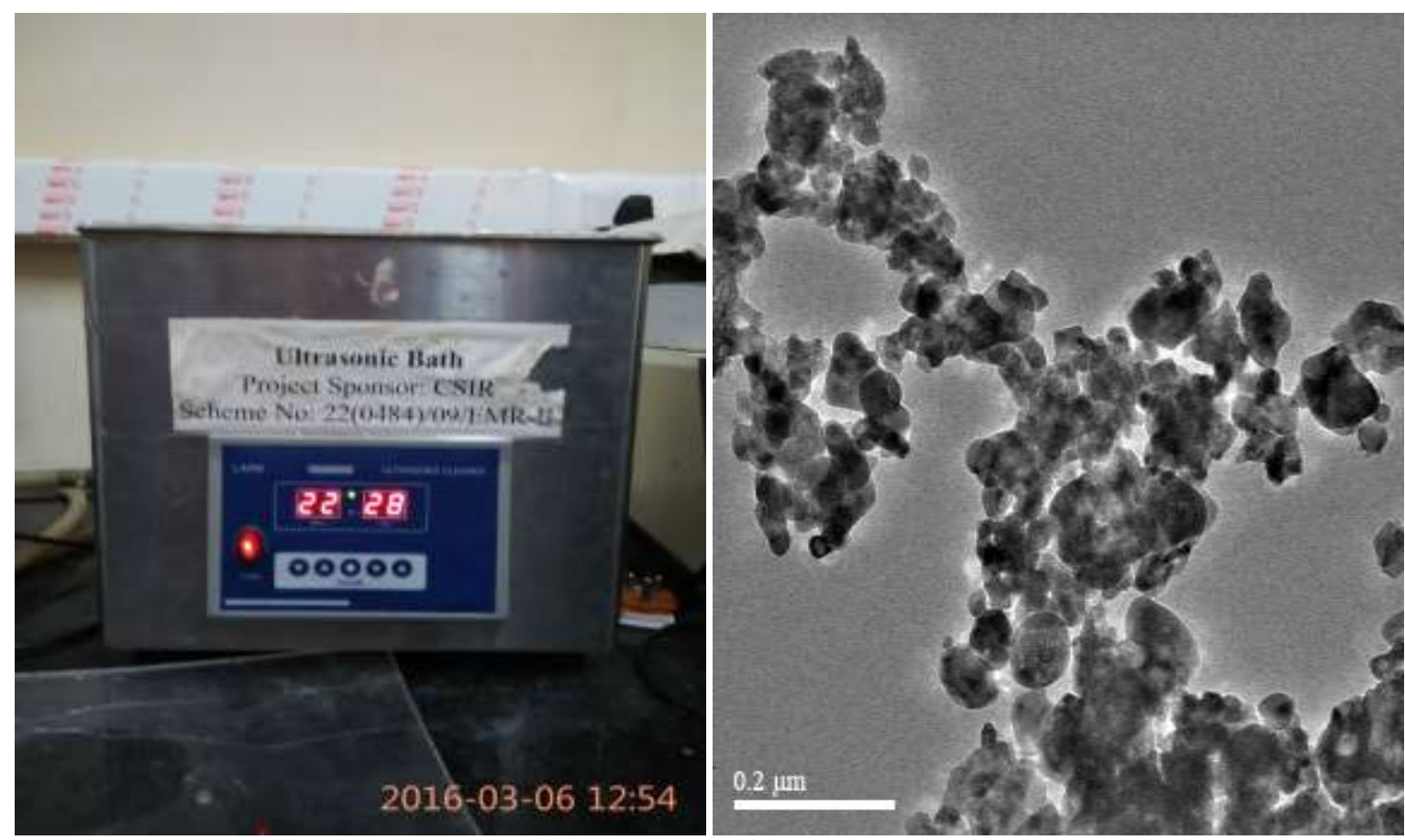

Fig. 1: Ultrasonic Bath Fig. 2:TEM image of $\mathrm{ZrO}_{2} / \mathrm{H}_{2} \mathrm{O}$ nanofluid

Bath type sonicator (Toshiba, India) shown in Fig. 1, employed for sonication generates ultrasonic pulses of $100 \mathrm{~W} . \mathrm{ZrO}_{2}$ nanoparticle is dispersed in $\mathrm{DI}$ water with $0.5,0.75$ and $1 \%$ particle volume concentrations, along with surfactant Yttrium Oxide. Initially the required volume of $\mathrm{ZrO}_{2}$ nanoparticle and surfactant added in DIwater stirred by magnetic stirrer for thirty minutes and then sonicated for two hours at temperature of $30^{\circ} \mathrm{C}$ by thesonicator. Fig. 2 shows TEM (Transmission Electron Microscopy) image of Zirconia/water nanofluid and it is evident that the nanoparticle average size of $20 \mathrm{~nm}$ and properly distributed in base fluid DI water.

\section{Thermo physical properties}

These properties are pivotal for heat transfer augmentation in nanofluid namely thermal conductivity (k),Dynamic viscosity $(\mu)$, density $(\rho)$ and specific heat $\left(\mathrm{C}_{p}\right)$

Thermal conductivity can be predicted by using Maxwell model[12] 


$$
k_{n f}=\frac{p+2 k_{b f}+2\left(k_{p}-k_{b f}\right) \varnothing}{k_{p}+2 k_{b f}-\left(k_{p}-k_{b f}\right) \varnothing} k_{b f}
$$

The viscosity predicted by a formula given by Einstien[13]

$$
\mu_{n f}=\mu_{b f}(1+2.5 \varnothing)
$$

Pak and Cho predicted the relation to determine the density of nanofluid [14]

$$
\rho_{n f}=\varnothing \rho_{p}+(1-\varnothing) \rho_{b f}
$$

Xuan and ruetzal evaluated the specific heat of nanofluid using the expression as follows[15]

$$
\left(\rho C_{p}\right)_{n f}=(1-\varnothing)\left(\rho C_{p}\right)_{f}+\varnothing\left(\rho C_{p}\right)_{p}
$$
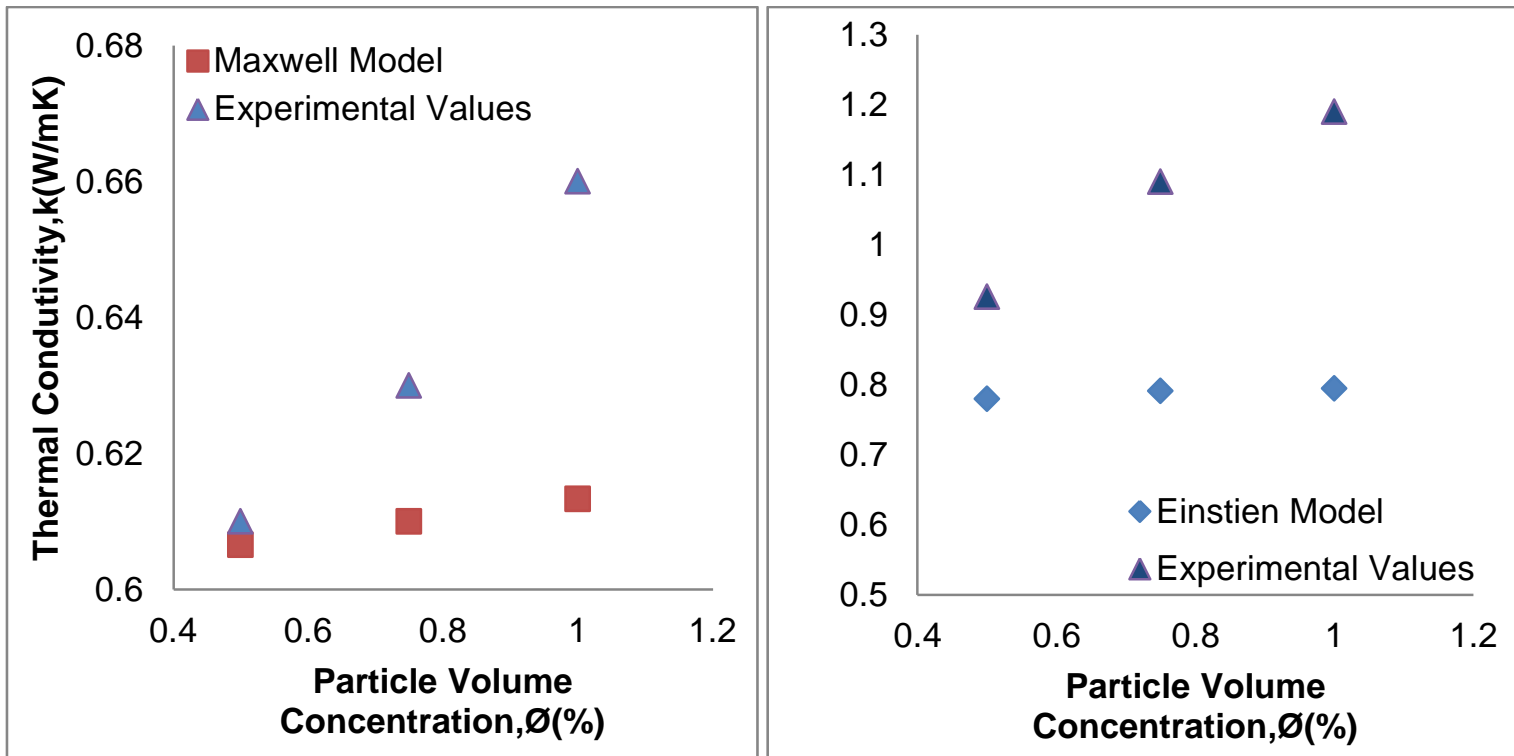

Fig 3: Comparison of Thermal conductivity and Viscosity of $\mathrm{ZrO}_{2} / \mathrm{H}_{2} \mathrm{O}$ with predicted model

Thermal conductivity and viscosity of nanofluid shown in Fig 3. KD2 pro thermal analyser is employed to read out the thermal conductivity, Firstly the thermal conductivity of base fluid DI water is measured as $0.6 \mathrm{~W} / \mathrm{m}-\mathrm{K}$, then $\mathrm{ZrO}_{2} / \mathrm{H}_{2}$ Onanofluid thermal conductivity is measured for three volume concentrations, it showed increase in thermal conductivity of $10 \%$ at $1 \%$ volume concentration, and also thermal conductivity of nanofluid gained with increase in volume concentration, and it has moderate agreement with predicted Maxwell model. Thermal conductivity of nanofluid increased due to the shape,size, volume fraction and Brownian motion of nanoparticle and also it depends on the $\mathrm{pH}$ value of the nanofluid. Viscosity of nanofluid is measured by using Brookfield cone and plate viscometer and it revealed that viscosity increased with increase of particle volume concentration.

\section{Experimental setup}

Experimental setup is shown in the Fig. 4. It consists of test section,calming section, riser section, cooling unit and pump .A straight $1000 \mathrm{~mm}$ length, $10 \mathrm{~mm}$ ID and $12 \mathrm{~mm}$ OD copper tube is used as a test section. It is surrounded by the Nichrome heating coil having the capacity of 400 watts. A thick insulation using glass wool material is insulated over the heating coil, five k-type thermocouples are located in axial distance of 150,300,600,750 and $900 \mathrm{~mm}$ from the entrance of test section for measuring the wall side temperature.Inlet and exit fluid temperatures are measured by two RTDs which are mounted at a distance of $15 \mathrm{~mm}$ of each side. Auto-transformer is used control the power input to the heater, U-tube manometer fixed to measure the pressure differences. Calming section is provided to achieve the fully developed layer in test section, Riser section is provided to overcome end effect of the fluid flow, cooling unit connected to cool the hot fluid, finally collected in a8 litres capacity tank. The centrifugal pump is used to circulate fluid in this loop. Rotameter measured the flow rate and flow rate can be controlled by a control valve. 

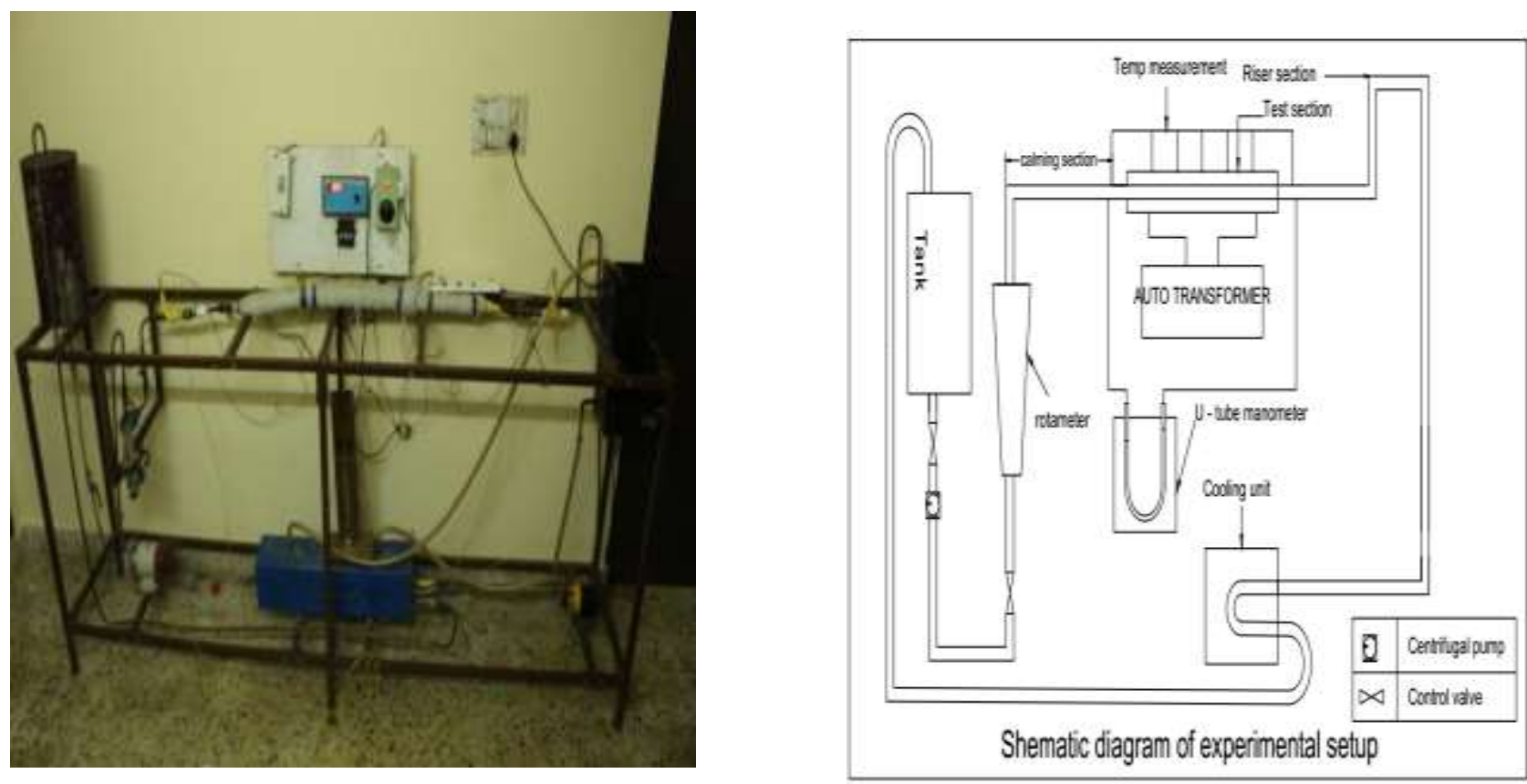

Fig.4: Photographical and schematic diagram of Experimental setup

\section{Experimental Procedure}

Experiments were carried out to evaluate the convective heat transfer and friction factor of water and nanofluid through the closed loop, the working fluid stored in the tank is circulated by the pump and the flow is regulated by the control valve. The voltage is varied by an auto-transformer to set the heat flux on the wall of the test section,this constant wall heat flux transferred to the flowing fluid thereby fluid gets heated. Initially water is allowed to flow for validation of the setup. By varying the voltage and flow rate the steady state is achieved simultaneously, temperatures on the wall side, inlet and outlet temperatures of the water are noted down. The same procedure is repeated for $\mathrm{ZrO}_{2} / \mathrm{H}_{2} \mathrm{Onanofluid}$ with different volume concentrations.

\section{Mathematical Formulations}

The heat supplied by the electrical winding is evaluated as

$$
\mathrm{Q}_{1}=\mathrm{VI}
$$

Where $\mathrm{V}$ is the voltage input, I is the current input to the electrical heater.

Heat gained by the fluid is evaluated as

$$
\mathrm{Q}_{2}=\mathrm{m} \mathrm{C}_{\mathrm{p}}\left(\mathrm{T}_{\text {out }}-\mathrm{T}_{\text {in }}\right)
$$

$m$ is the mass flow rate, $C_{p}$ is the specific heat of fluid, $T_{\text {in }}$ and $T_{\text {out }}$ are inlet and outlet temperatures of the fluid.

Experimental nusselt number evaluated by the below equations.

Average heat transfer

$$
Q=\left(Q_{1}+Q_{2}\right) / 2
$$

Heat flux

$$
q=\frac{Q}{\pi D L}
$$

Heat transfer coefficient

$$
h=\frac{q}{\left(T_{w}-T_{f}\right)}
$$

Nusselt number

$$
N u=\frac{h D}{k}
$$


Where $D$ is diameter of the test section, $L$ is length of the test section, $T_{w}$ is the average wall temperature, $T_{f}$ is the average fluid temperature.

$$
f=\frac{\Delta p}{\left(\frac{L}{D}\right)\left(\rho u^{2}\right)}
$$

Where $\Delta p$ is pressure difference in the test section,pis density and $u$ is the velocity of the working fluid .

\section{Results and discussion}

\section{Validation of Experimental setup}

The experimental setup is validated by experimental values of DI Water, obtained in terms of Nusselt number and friction factor compared with existing correlations proposed by Shah and Hagen Poiseuille for laminar flow. Besides Reynolds number ranges from 600 to 2100 .

Shah equation is given below

$$
\begin{gathered}
\mathrm{Nu}=1.953\left(\operatorname{Re} \operatorname{Pr} \frac{D}{x}\right)^{1 / 3} \quad \text { for }\left(\operatorname{Re} \operatorname{Pr} \frac{D}{x}\right) \geq 33.33 \\
\mathrm{Nu}=4.364=0.0722\left(\operatorname{Re} \operatorname{Pr} \frac{D}{x}\right) \text { for }\left(\operatorname{Re} \operatorname{Pr} \frac{D}{x}\right)<33.33
\end{gathered}
$$

Hagen Poiseuille equation is

$$
f=\frac{64}{R e}
$$

The experimental Nusselt number is compared with Shah equation and results are in good agreement as shown in Fig.5. Fig.6 shows that comparison of experimental friction factor values with Hagen poissullie equation are also in good agreement with plain tube data.

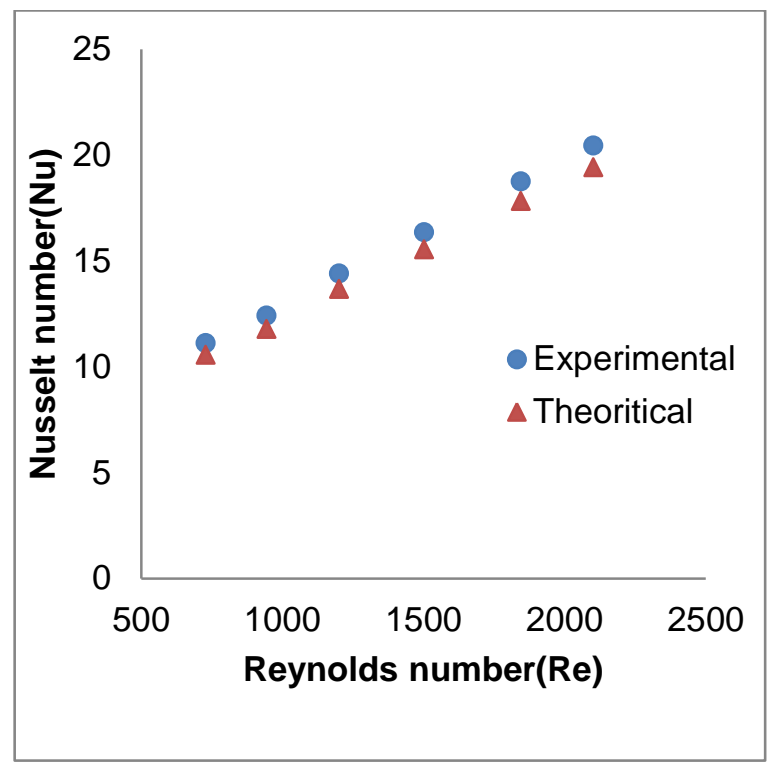

Fig. 5:Comparison of experimental nusselt number with Shah equation 


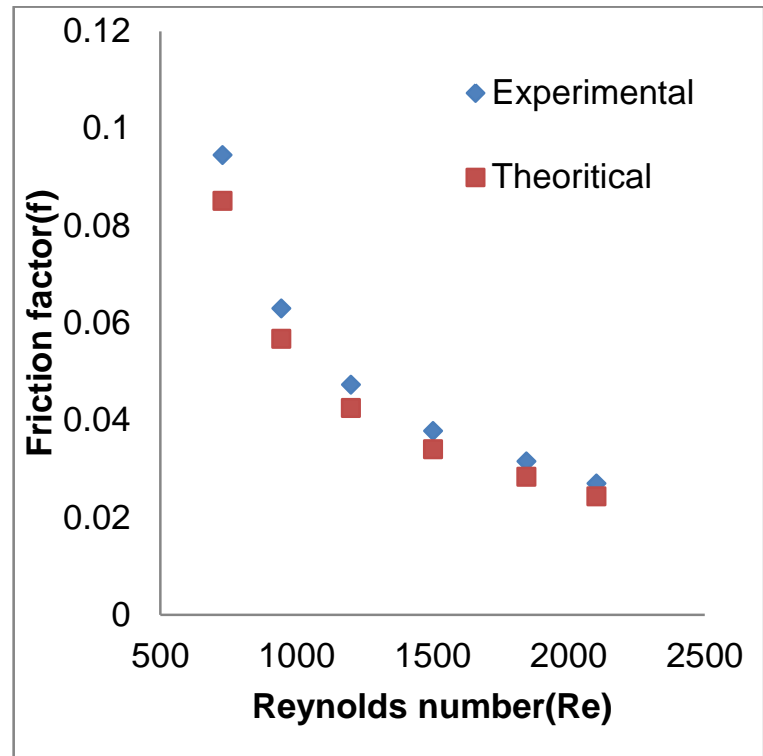

Fig. 6:Comparision of experimental friction factor with Hagen poiseiulle equation

\section{Heat transfer study}

Fig. 7 shows the nusselt number variation with Reynolds number, results are revealed that the heat transfer enhancement are higher than the base fluid DI Water due to the increase in thermal conductivity of Zirconia nanoparticle present in the DI Water and collision among the nanoparticles so that heat transfer rate is increased. Tests are carried out for $0.5,0.75$ and $1 \%$ particle volume concentrations. These three nanofluidvolume concentrations exhibited heat transfer characteristics higher than DI water and also exhibited increased Nusselt number values of 21.09, 28.05 and $35.73 \%$ respectively.

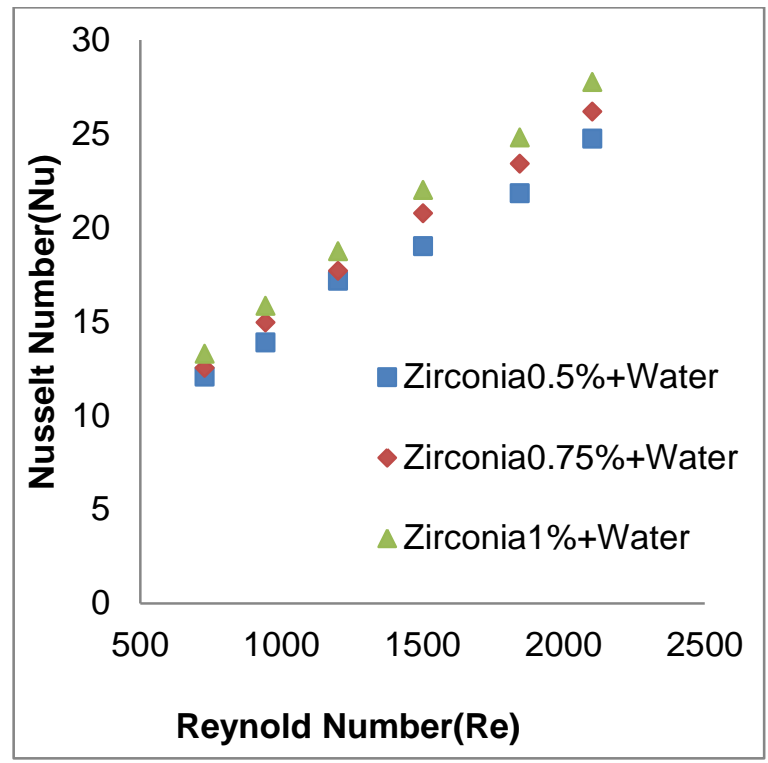

Fig 7:Variation of nusselt number with Reynolds number

\section{Friction factor study}

The pressure drop of nanofluid is measured by means of U-tube manometer. Pressure drop is measured between entry and exit of the fluid in the test section to evaluate friction factor.Fig. 8 shows variation of friction factor with Reynolds number. Nanofluid friction factor does not show much difference comparedto base fluid. It is observed that the small pressure drop increased due to the particle volume concentration and also no excess penalty on pumping power. However, if the flow rate increased then friction factordecreased. 


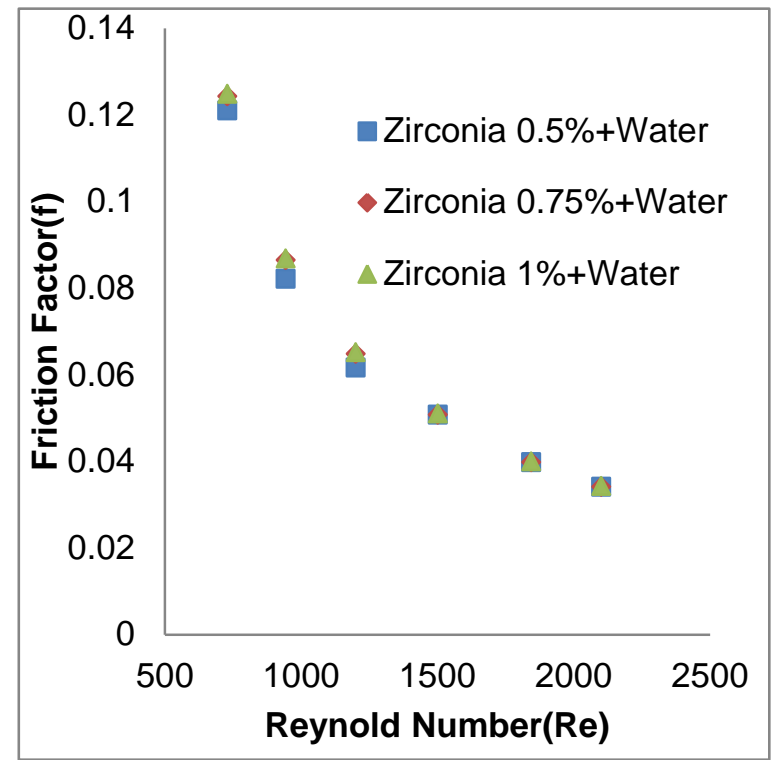

Fig 8:Variation of friction factor with Reynolds number

\section{Conclusions}

This study investigated heat transfer enhancement and pressure drop evaluation of $\mathrm{ZrO}_{2} / \mathrm{H}_{2} \mathrm{O}$ nanofluid. Experiments are carried out in a fully developed laminar flow regime with constant heat flux in the range of 600 to 2100 Reynolds number at $0.5,0.75$ and $1 \%$ volume concentrations. Experimental results are compared with plain tube data and the following observations were obtained.

i) Thermo physical properties like thermal conductivity and viscosity of the nanofluid showed notable augmentation with increased volume concentration.

ii) The particle volume concentration and Reynold number are responsible for the heat transfer enhancement of the system

iii) These conditions yielded enhanced Nusselt number of $35.73 \%$ at $1 \%$ volume concentration.

This concluded that the $\mathrm{ZrO}_{2} / \mathrm{H}_{2} \mathrm{O}$ nanofluid is suitable as working fluid for the heat transfer applications. Further, this experimental work is extended with inserts for the better heat transfer performance.

\section{REFERENCES}

[1] StephenU.S. Choi and Jeffrey A. Eastman, Enhancing thermal conductivity of fluids with nanoparticles.ASME International mechanical engineering congress\&exposition. November 12-17.1995. San Fransisco,CA.

[2] B.C. Pak and Cho, Hydrodynamic and heat transfer study of dispersed fluids with submicron metallic oxide particles , Experimental heat transfer , 11:151-170,1998.

[3] P. Keblinski, S,R.Phillpot, Mechanism of heat flow in suspensions of nano-sized particles (nanofluids), International journal of heat and mass transfer 45 (2002) 855-863

[4]S.K.Das. Temperature dependence of thermal conductivity enhancement for nanofluids.Journal of heat transfer,(2003),vol.125(567-574).Volume 19, Issue 1, March 2016, Pages 574-586

[5] Yimin Xuan and QiangLi , Investigation on convective heat and flow features of nanofluids, journal of heat transfer (2003),vol. 125(151-155)

[6] NileshPurohit and Varun AnandPurohit, Assessment of nanofluids for laminar convective heat transfer :A numerical study, Engineering science and Technology , an International journal. Volume 19, Issue 1, March 2016, Pages 574-58

[7] AminrezaNoghrehabadi and Rashid Purrajab, Experimental investigation of forced convective heat transfer enhancement of g-Al2O3/water nanofluid in a tube, journal of mechanical science and technology 30(2) (2016) 943-952.

[8] M.A. Khairul and kalpit Shah, Effects of surfactant on stability and thermo-physical properties of metal oxide nanoflids , International journal of heat and mass transfer 98(2016) 7788-787.

[9] B.Chitra and K.Satishkumar,Heat transfer enhancement using single base and double base nanofluids, journal of molecular liquids 21(2016) 1128-1132.

[10]M Chopkar, PK Das , Thermal characterization of nanofluid comprising nanocrystalline ZrO2 dispersed in water and ethylene glycol,Philosophical magazine 13/09/2007. 
[11]Wesley Williams, Jacopo Buongiriono, Lin-wen Hu. Experimental investigation of turbulent convective heat transfer of Alumina/water and Zirconia/water nanoparticle colloids in horizontal tubes, Journal of Heat Transfer APRIL 2008, Vol. 130 / 042412-7

[12]Maxwell, J. C., Treatise on Electricity and Magnetism, Vol. 2, Reprint by Dover, Mineola, N. Y., USA, 1954

[13] Einstein, A., Investigations on the Theory of Brownian Motion, Methuen and Co., Ltd., London, 1926, Reprint by Dover Publications, Mineola, N. Y., USA, 1956

[14] Pak, B. C., Cho, Y. I., Hydrodynamic and Heat Transfer Study of Dispersed Fluids with Submicron Metallic Oxide Particles, Experimental Heat Transfer an International Journal, 11 (1998), 2, pp. 151-170

[15]Xuan, Y., Roetzel, W., Conceptions for Heat Transfer Correlation of Nanofluids, International Journal of Heat and MassTransfer,43(2000),19,pp.3701-3707 